Check for updates

Cite this: RSC Adv., 2017, 7, 52517

Received 20th September 2017 Accepted 8th November 2017

DOI: $10.1039 / c 7 r a 10448 k$

rsc.li/rsc-advances

\title{
Tuning the electrical performance and bias stability of a semiconducting SWCNT thin film transistor with an atomic layer deposited $\mathrm{AlZrO}_{x}$ composite
}

\begin{abstract}
Jun Li, ${ }^{\text {ab }}$ Chuan-Xin Huang ${ }^{a}$ and Jian-Hua Zhang $\mathbb{D}^{* b}$
Solution-processed semiconducting single-walled carbon nanotube (s-SWCNT) thin film transistors (TFTs) based on different atomic layer deposited $\mathrm{AlZrO}_{x}$ insulators are fabricated and characterized. It is found that increasing the $\mathrm{Al}$ concentration in the $\mathrm{AlZrO}_{x}$ insulator can reduce leakage current and decrease the surface roughness of the $\mathrm{AlZrO}_{x}$ insulator. Compared with the device with a $\mathrm{ZrO}_{2}$ insulator, the electrical performance, including subthreshold swing, $I_{\text {on }} / I_{\text {off }}$ and hysteresis, and negative bias stability of s-SWCNT TFTs with the $\mathrm{AlZrO}_{x}$ insulator has been significantly improved. The s-SWCNT TFT based on AlZrO ${ }_{x}$ with a $\mathrm{ZrO}_{2} / \mathrm{Al}_{2} \mathrm{O}_{3}$ cycle ratio of $1 / 2$ reveals a superior electrical performance with an average mobility of 35.2 $\mathrm{cm}^{2} \mathrm{~V}^{-1} \mathrm{~s}^{-1}$, a high on/off ratio of $3.7 \times 10^{5}$, a low subthreshold swing of 0.09 , a small hysteresis of $0.1 \mathrm{~V}$, and a small threshold voltage shift of $1.62 \mathrm{~V}$ under a negative bias stress of $-3 \mathrm{~V}$ for $1800 \mathrm{~s}$. The improvement of electrical performance and stability for the s-SWCNT TFT with the AIZrO $\mathrm{A}_{x}$ insulator is attributed to the smooth surface and less $\mathrm{AlZrO}_{x} / \mathrm{s}-\mathrm{SWCNT}$ interface traps. Our results suggest that using a $\mathrm{AlZrO}_{x}$ film as a gate insulator can be a useful technique to achieve high performance and more reliable solution-processed s-SWCNT TFTs.
\end{abstract}

\section{Introduction}

Single-walled carbon nanotube (SWCNT) thin film transistors (TFTs) have shown potential in the next generation flexible electronic devices due to their high carrier mobility, high chemical stability, transparency and excellent mechanical properties. $^{1-3}$ However, conventional SWCNTs contain both metallic and semiconducting SWCNTs, which results in a poor on/off current ratio and high off state current. ${ }^{4-8}$ In order to improve the on/off current ratio, solution-processed preseparated high-purity semiconducting SWCNTs were recently reported for high performance TFTs. Selective removal of metallic CNTs via electrical breakdown has been studied to increase the on/off current ratio. However, these methods cause serious destruction of the remaining nanotubes in the networks. ${ }^{9-11}$ In order to achieve low-cost fabrication, solution processed semiconducting SWCNTs have been used for application in transistors. Many methods, such as gradient ultracentrifugation, ${ }^{\mathbf{1 2 , 1 3}}$ gel chromatography, ${ }^{\mathbf{1 4 1 5}}$ and selective extraction by conjugated polymers, ${ }^{16,17}$ have demonstrated the effective isolation of semiconducting SWCNTs. Despite the separation of metallic and semiconducting SWCNTs, the choice

${ }^{a}$ School of Material Science and Engineering, Shanghai University, Jiading, Shanghai 201800, People's Republic of China

${ }^{b}$ Key Laboratory of Advanced Display and System Applications, Ministry of Education, Shanghai University, Shanghai 200072, People's Republic of China. E-mail: jhzhang_li@163.com of gate dielectric is still a key issue in electrical improvement of semiconducting SWCNT TFTs because the electrical properties of SWCNT-TFTs are strongly dependent on the surface conditions, dielectric constant and leakage current of the dielectric layer. In previous works, thermally grown $\mathrm{SiO}_{2}$ gate insulator is frequently studied for semiconducting SWCNT TFT. However, the process temperature and low dielectric constant of thermally grown $\mathrm{SiO}_{2}$ insulator is difficult to require the demand of high performance and flexible SWCNT TFT. ${ }^{18}$ High k materials, such as $\mathrm{ZrO}_{2},{ }^{19} \mathrm{HfO}_{2},{ }^{20}$ have been prepared for high performance SWCNT TFT. Although $\mathrm{ZrO}_{2}$ shows a high permittivity of 20-25, it suffers from its high leakage current due to a narrow band gap and existing oxygen vacancies. To address this disadvantage, cation doping is considered as a feasible method to improve band gap and suppress oxygen vacancies of $\mathrm{ZrO}_{2}$. Recently, yttrium-scandium oxide high-k dielectric is deposited by a solution process for TFT application. ${ }^{21}$ Sputtered amorphous strontium titanate film can be used as gate insulator of low-voltage TFTs. ${ }^{22}$ Furthermore, $\mathrm{Al}_{2} \mathrm{O}_{3}$ is a promising gate dielectric material because of its amorphous structure, lowleakage current, acceptable dielectric constant (6.5-9), and wide band gap (5.6-7.8 eV). ${ }^{23}$ Combining both advantages of $\mathrm{ZrO}_{2}$ and $\mathrm{Al}_{2} \mathrm{O}_{3}$, it is expected to develop a novel dielectric material $\mathrm{AlZrO}_{x}$ to meet the requirement of high performance semiconducting SWCNT TFTs. Compared to other deposition methods, atomic layer deposition (ALD) is capable of producing high quality conformal film with control of the thickness and composition of the films at the atomic level. ${ }^{24}$ Ultimately, $\mathrm{AlZrO}_{x}$ 
gate dielectric with high dielectric constant and low leakage current can be optimized by tuning the Al content.

In the work, $\mathrm{AlZrO}_{x}$ high-k gate insulators with different $\mathrm{Al}$ contents are firstly prepared and semiconducting SWCNT TFTs with different $\mathrm{AlZrO}_{x}$ insulators were fabricated. The influence of $\mathrm{Al}$ content on the electrical performance, structure, and surface topography of $\mathrm{AlZrO}_{x}$ insulators are investigated. The electrical performance and temperature stress stability of SWCNT TFTs with different $\mathrm{AlZrO}_{x}$ insulators are analyzed. The work aims to supply a facile strategy to enhance performance and bias stability of semiconducting SWCNT thin film transistor with atomic layer deposited $\mathrm{AlZrO}_{x}$ composite.

\section{Experimental}

The bottom gate top-contact-type TFTs were fabricated on the highly-doped Si substrate with $\mathrm{ZrO}_{2}$ and $\mathrm{AlZrO}_{x}$ thin films grown by atom layer deposition as gate insulators. The structure of device is shown in Fig. 1(a). During deposition process, precursors for $\mathrm{Zr}, \mathrm{Al}$ and $\mathrm{O}$ were Tetrakis dimethyl amino zirconium (TDMAZr), $\mathrm{Al}\left(\mathrm{CH}_{3}\right)_{3}$ (TMA), and $\mathrm{H}_{2} \mathrm{O}$, respectively. TDMAZr and TMA precursors are purchased from Jiangsu Fu Na Electronic Technology Co., Ltd (China) and Air Liquid Holding Co. Ltd (France). The deposition temperature is about $250{ }^{\circ} \mathrm{C}$. Typical pulsing sequences during ALD process are 1/5/3/5 $\mathrm{S}$ (TDMAZr/Ar purge/ $\mathrm{H}_{2} \mathrm{O} /$ Ar purge) and 1/4/2/5 s (TMA/Ar purge/ $\mathrm{H}_{2} \mathrm{O}$ /Ar purge) for the growth of $\mathrm{ZrO}_{2}$ and $\mathrm{Al}_{2} \mathrm{O}_{3}$ film, respectively. The Al doping concentration in the $\mathrm{AlZrO}_{x}$ film was controlled by adjusting the cycle ratio of the $\mathrm{Al}_{2} \mathrm{O}_{3}$ and $\mathrm{ZrO}_{2}$ processes. The cycle ratio of $\mathrm{ZrO}_{2}$ and $\mathrm{Al}_{2} \mathrm{O}_{3}$ are 2/1, 1/1, and 1/2 for $\mathrm{AlZrO}_{x-1}, \mathrm{AlZrO}_{x-2}$, and $\mathrm{AlZrO}_{x-3}$, respectively. The thickness of all $\mathrm{AlZrO}_{x}$ films was controlled by the total deposition cycles and fixed at $170 \mathrm{~nm}$. For the $\mathrm{Al}_{2} \mathrm{O}_{3}$ and $\mathrm{ZrO}_{2}$ film, the overall reactions between the precursors and the surface can be shown: ${ }^{25,26}$

$$
\begin{gathered}
2 \mathrm{Al}\left(\mathrm{CH}_{3}\right)_{3}+3 \mathrm{H}_{2} \mathrm{O} \rightarrow \mathrm{Al}_{2} \mathrm{O}_{3}+3 \mathrm{CH}_{4} \\
\mathrm{Zr}\left(\mathrm{N}_{(}\left(\mathrm{CH}_{3}\right)_{2}\right)_{4}+2 \mathrm{H}_{2} \mathrm{O} \rightarrow \mathrm{ZrO}_{2}+4 \mathrm{H}\left(\mathrm{N}\left(\mathrm{CH}_{3}\right)_{2}\right)
\end{gathered}
$$

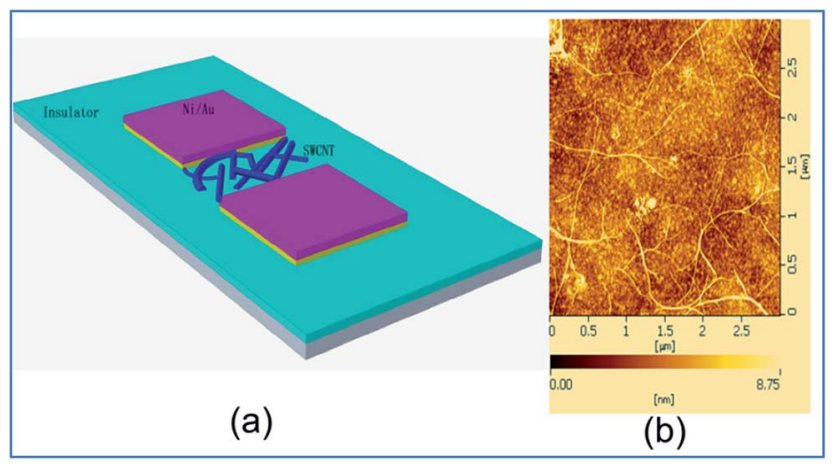

Fig. 1 (a) Schematic structure of Semiconducting SWCNT thin film transistors. (b) The surface morphology of the semiconducting SWCNTS by AFM.
The Ni (10 nm)/Au (90 nm) source and drain electrodes were patterned onto the $\mathrm{Si} / \mathrm{AlZrO}_{x}$ wafer by a photolithography process with the channel width $(W)$ of $20 \mu \mathrm{m}$ and channel length $(L)$ of $10 \mu \mathrm{m}$. Next, the well-sonicated 99.9\% semiSWCNTs (Nanointegris, Arc discharge nanotube, average diameter range of $1.4 \mathrm{~nm}$ and average length of $1 \mu \mathrm{m}$ ) precursor solution was drop-casted onto the channel region as the active material of p-channel transistors with the solution concentration of $0.1 \mathrm{mg} \mathrm{mL}^{-1}$ and the volume of $20 \mu \mathrm{L}$ at room temperature. The semiconducting SWCNTs were enriched by polymer extraction, so the channel region was cleaned by toluene to remove the polymer. The surface morphology of the semiconducting SWCNTs is shown in Fig. 1(b).

The thickness of thin film was measured by the alpha step (Alpha-Step IQ). The electrical characteristics of semi-SWCNTs TFTs were measured using Agilent E3647A Dual output DC power supply and Keithley 6485 Picoammeter. The capacitance characteristics were measured by Agilent E4980A LRC meter. The surface morphology of thin films was investigated using atomic force microscopy (SII NanoTechnology SPI 4000) with tapping mode. The roughness parameters are as measured over $1.5 \times 1.5 \mu \mathrm{m}^{2}$, and evaluated using the software supplied with the instrument. The structure of $\mathrm{AlZrO}_{x}$ thin films was measured by grazing incidence X-ray diffraction (GIXRD) scans using $\mathrm{Cu} \mathrm{K} \alpha$ radiation. The X-ray source was composed of a sealed X-ray tube, a multilayer monochromator able to select a parallel beam of $\mathrm{Cu} \mathrm{K} \alpha$ radiation and a system of crossed slits defining a beam of appropriate size. GIXRD spectra were collected on a position sensitive detector (Inel CPS120). The angle of incidence $\omega=0.5^{\circ}$ was chosen as not widely exceeding the critical angle for total external reflection of $\mathrm{AlZrO}_{x}$. The chemical bonding states of films were carried out with the X-ray photoelectron spectroscopy (XPS) (Thermo-ESCALAB250XL)) in ultrahigh vacuum (UHV).

\section{Results and discussion}

Fig. 2(a) shows the GIXRD patterns of $\mathrm{AlZrO}_{x}$ films with different $\mathrm{Al}$ contents. In the previous work, ${ }^{27}$ it is verified that $\mathrm{ZrO}_{2}$ film shows a crystalline structure with a sharp diffraction peak of 35.2 ${ }^{\circ}$. When $\mathrm{Al}$ content is doped into $\mathrm{ZrO}_{2}$ film, diffraction peak is not observed in the XRD patterns. It suggests that $\mathrm{AlZrO}_{x}$ film shows the amorphous nature. The crystallization-to-amorphous transition is achieved by adding a suitable dopant, because the original bond structure order is distorted..$^{28}$ In addition, the amorphous $\mathrm{AlZrO}_{x}$ film is suitable to prepare large-size and uniform thin films. The insulating properties of $\mathrm{AlZrO}_{x}$ films with different $\mathrm{Al}$ content are characterized by measuring the leakage current versus bias voltage, as shown in Fig. 2(b). The leakage current density of $\mathrm{ZrO}_{2}$ thin film is $2.2 \times 10^{-8} \mathrm{~mA} \mathrm{~cm}^{-2}$ at the electrical field strength of $2 \mathrm{MV} \mathrm{cm}^{-1}$. The increased leakage current density is attributed to crystalline grain boundaries of $\mathrm{ZrO}_{2}$, which can acts as current leakage paths and defect/ break-down centers. ${ }^{29}$ For comparison, the leakage current density of $\mathrm{AlZrO}_{x}$ film is decreased with increasing Al content. The leakage current density of $\mathrm{AlZrO}_{x-3}$ thin film is $3.5 \times 10^{-9}$ $\mathrm{mA} \mathrm{cm}{ }^{-2}$ at the electrical field strength of $2 \mathrm{MV} \mathrm{cm}^{-1}$. The value 

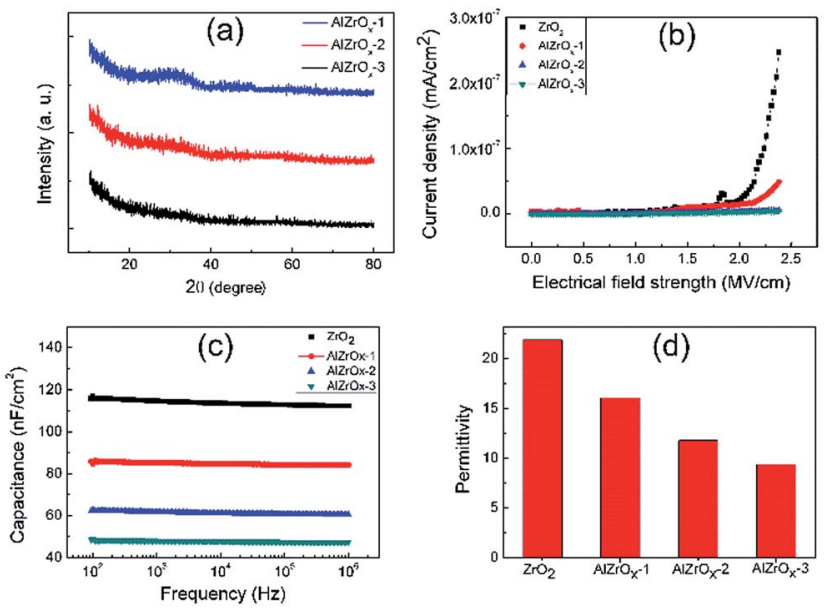

Fig. 2 (a) The GIXRD patterns of $\mathrm{AlZrO}_{x}$ films with different $\mathrm{Al}$ contents. (b) The leakage current versus bias voltage of $\mathrm{AlZrO}_{x}$ films. (c) The areal capacitance of $A I Z r O_{x}$ film as a function of the frequency. (d) The dielectric permittivity of $\mathrm{AlZrO}_{x}$ and $\mathrm{ZrO}_{2}$ film.

is better than that of other high-k insulators by sputtering and solution process. ${ }^{\mathbf{3 0 , 3 1}}$ To characterize the capacitance properties of $\mathrm{AlZrO}_{x}$ thin films, a capacitor with the structure of $\mathrm{Al} / \mathrm{AlZrO}_{x} /$ $\mathrm{p}^{+}-\mathrm{Si}$ is prepared. Fig. 2(c) shows the areal capacitance of $\mathrm{AlZrO}_{x}$ film as a function of the frequency. The capacitance of $\mathrm{ZrO}_{2}$, $\mathrm{AlZrO}_{x-1}, \mathrm{AlZrO}_{x-2}$, and $\mathrm{AlZrO}_{x-3}$ at a frequency of $1 \mathrm{kHz}$ is 114.0, 84.1, 61.5, and $48.2 \mathrm{nF} \mathrm{cm}{ }^{-2}$, respectively. $\mathrm{AlZrO}_{x}$ films show a smaller frequency dispersion of the capacitance than $\mathrm{ZrO}_{2}$ film, indicating that $\mathrm{AlZrO}_{x}$ films exhibit a low defect density and oxygen vacancies. The similar results were reported by the previous work..$^{32,33}$ T. J. Park et al. have also verified that $\mathrm{Al}$ doping can reduce the electrical defects in atomic layer deposited $\mathrm{HfO}_{2}$ films. ${ }^{34}$ The dielectric permittivity $\left(\varepsilon_{\mathrm{r}}\right)$ can be calculated by the following equation: $C=\varepsilon_{0} \varepsilon_{\mathrm{r}} S / d$, where $S$ is the area, $d$ is the thickness of film. The dielectric permittivity of $\mathrm{ZrO}_{2}$, $\mathrm{AlZrO}_{x-1}, \mathrm{AlZrO}_{x-2}$ and $\mathrm{AlZrO}_{x-3}$ thin film are 21.9, 16.1, 11.8 and 9.7, respectively. The details are shown in Fig. 2(d). The dielectric permittivity of $\mathrm{AlZrO}_{x}$ film decreases with increasing $\mathrm{Al}$ content. It can be explained by considering the dielectric constants of $\mathrm{Al}_{2} \mathrm{O}_{3}$ and $\mathrm{ZrO}_{2}$.

Fig. 3 shows XPS spectra of $\mathrm{Zr} 3 \mathrm{~d}$ and $\mathrm{Al} 2 \mathrm{p}$. All the XPS peaks are calibrated with $\mathrm{C} 1 \mathrm{~s}$ peak centered at $284.8 \mathrm{eV}$. As shown in Fig. 2(a), the peak positions of $\mathrm{Zr} 3 \mathrm{~d}_{5 / 2}$ and $\mathrm{Zr} 3 \mathrm{~d}_{3 / 2}$ for $\mathrm{ZrO}_{2}$ film are at $181.9 \mathrm{eV}$ and $184.3 \mathrm{eV}$, respectively. The binding energy of
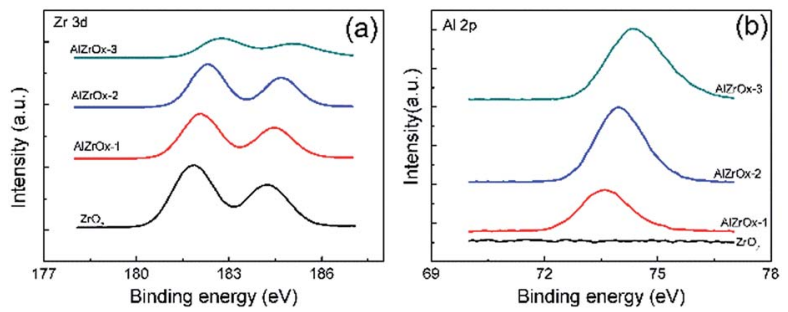

Fig. 3 XPS spectra of the samples with various Al contents: (a) Zr 3d. (b) Al 2p.
Al 2p of $\mathrm{AlZrO}_{x-1}, \mathrm{AlZrO}_{x-2}$, and $\mathrm{AlZrO}_{x-3}$ is 73.6, 74.0, and $74.3 \mathrm{eV}$, respectively. It is easily seen that the binding energy of $\mathrm{Al} 2 \mathrm{p}$ of all $\mathrm{AlZrO}_{x}$ films are lower than that of $\mathrm{Al}_{2} \mathrm{O}_{3}(74.8 \mathrm{eV}){ }^{35,36}$ Both $\mathrm{Zr} 3 \mathrm{~d}$ and $\mathrm{Al} 2 \mathrm{p}$ peaks for $\mathrm{AlZrO}_{x}$ thin films shift to higher binding energy with increasing $\mathrm{Al}$ concentration. It is found that the leading contribution is the charge transfer contribution. The charges transfer can be estimated with DFT-LDA calculations. The similar result is previously reported. ${ }^{37}$ In addition, it suggests that the $\mathrm{AlZrO}_{x}$ films mainly consist of $\mathrm{Zr}$ $\mathrm{O}-\mathrm{Al}$ bonds and present a homogenous structure with negligible phase-separated $\mathrm{ZrO}_{2}$ and $\mathrm{Al}_{2} \mathrm{O}_{3}$. The similar result is reported by other groups. ${ }^{18}$ The real concentrations of $\mathrm{Al}$ are $20.99 \%, 25.74 \%$, and $30.0 \%$ for $\mathrm{AlZrO}_{x-1}, \mathrm{AlZrO}_{x-2}$, and $\mathrm{AlZrO}_{x-3}$, respectively.

Fig. 4 shows the AFM images of $\mathrm{AlZrO}_{x}$ insulators with different $\mathrm{Al}$ content. The root mean square (rms) of $\mathrm{ZrO}_{2}$, $\mathrm{AlZrO}_{x-1}, \mathrm{AlZrO}_{x-2}$ and $\mathrm{AlZrO}_{x-3}$ film is 1.2, 0.86, 0.66 and $0.46 \mathrm{~nm}$, respectively. It suggests that $\mathrm{Al}$ doping can reduce rms of $\mathrm{AlZrO}_{x}$ film and improve the surface roughness of $\mathrm{AlZrO}_{x}$. In previous XRD analysis, $\mathrm{Al}$ doping can suppress the formation of grain boundaries. It is reported that smooth insulator surface could induce much less interface defects and obtain a better insulator-channel interface, which leads to higher mobility of TFTs. ${ }^{38}$ Thus, smooth $\mathrm{AlZrO}_{x}$ insulator is expected to fabricate high performance semiconducting SWCNT TFTs.

Fig. 5 shows the transfer characteristics and hysteresis of semiconducting SWCNT TFTs with different $\mathrm{AlZrO}_{x}$ insulators. The transfer characteristic of SWCNT TFTs is measured between gate voltage of $3 \mathrm{~V}$ and $-3 \mathrm{~V}$ with a fixed drain bias voltage of $-3 \mathrm{~V}$. The low operating voltage suggests that it is suitable to fabricate electronic devices with low power consumption. The turn-on voltage $\left(V_{\text {on }}\right)$ shows a negative voltage direction shift with the increase in the $\mathrm{Al}$ concentration. It is ascribed to the decrease in capacitance with the increase in the Al concentration of $\mathrm{AlZrO}_{x}$ film. The field mobility $(\mu)$ and threshold voltage $\left(V_{\mathrm{T}}\right)$ can be extracted from the following equation ${ }^{39}$
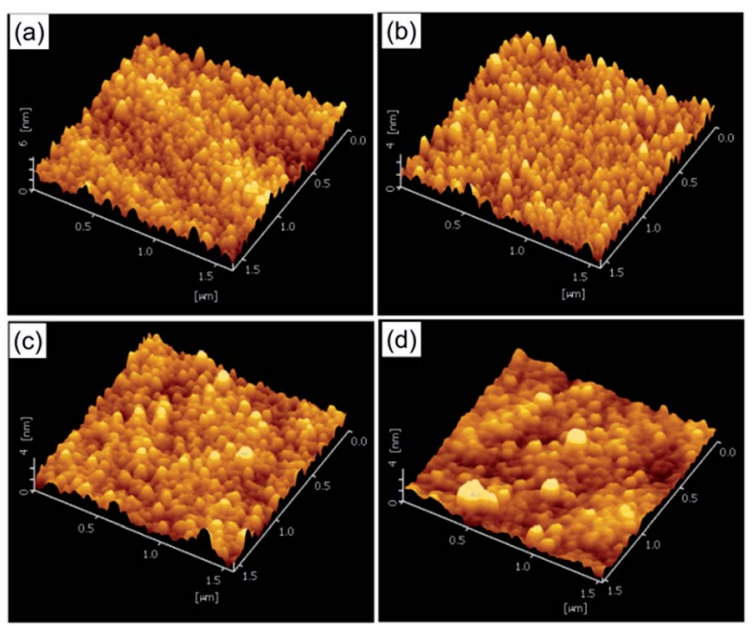

Fig. 4 The AFM images of $\mathrm{AlZrO}_{x}$ insulators with different $\mathrm{Al}$ content. (a) $\mathrm{ZrO}_{2}$, (b) $\mathrm{AlZrO}_{x-1}$, (c) $\mathrm{AlZrO}_{x-2}$, (d) $\mathrm{AlZrO}_{x-3}$. 

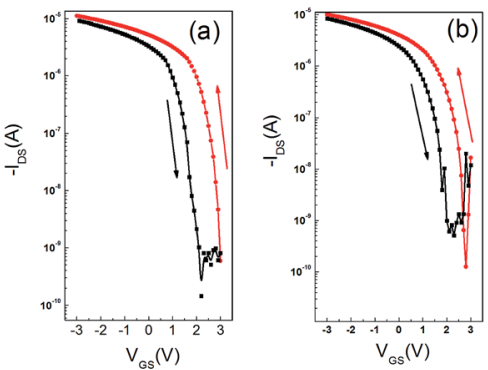

$$
V_{G S}(V)
$$
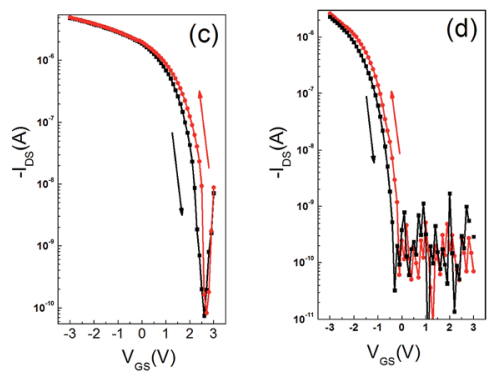

Fig. 5 The transfer characteristics and hysteresis of semiconducting SWCNT TFTs with different gate insulators. (a) $\mathrm{ZrO}_{2}$, (b) $\mathrm{AlZrO}_{x-1}$, (c) $\mathrm{AlZrO}_{x-2}$, (d) $\mathrm{AlZrO}_{x-3}$.

$$
I_{\mathrm{DS}}=\left(V_{\mathrm{GS}}-V_{\mathrm{T}}\right)^{2} \times W \mu C_{\mathrm{i}} / 2 L, V_{\mathrm{DS}}>V_{\mathrm{GS}}-V_{\mathrm{T}}
$$

where $I_{\mathrm{DS}}$ is the drain-source current, $W$ is the width of channel, $L$ is the length of channel, $V_{\mathrm{GS}}$ is the gate voltage, and $C_{\mathrm{i}}$ is the intrinsic capacitance. For SWCNT transistors, the intrinsic capacitance can be calculated using eqn (4) by considering the effect of electrostatic coupling between semi-SWCNTs. ${ }^{40}$

$$
C_{\mathrm{i}}=\left\{\frac{1}{2 \pi \varepsilon_{0} \varepsilon_{\mathrm{i}}} \times \ln \left[\frac{\Lambda_{0}}{R} \times \frac{\sinh \left(\frac{2 \pi t_{\mathrm{i}}}{\Lambda_{0}}\right)}{\pi}\right]+\frac{1}{C_{\mathrm{Q}}}\right\}^{-1} \times \Lambda_{0}^{-1}
$$

where $\varepsilon_{0}$ is the vacuum permittivity, $\varepsilon_{\mathrm{i}}$ is dielectric constant of dielectric layer, $t_{\mathrm{i}}$ is the thickness of dielectric layer, $C_{\mathrm{Q}}=$ $4 \times 10^{-10} \mathrm{~F} \mathrm{~m}^{-1}$ is the quantum capacitance of semi-SWCNTs, $R=1 \mathrm{~nm}$ is the average radius of semi-SWCNTs and $\Lambda_{0}{ }^{-1}=2.25$ tubes per $\mu \mathrm{m}$ is the linear density of semi-SWCNTs. In our case, the calculated intrinsic capacitance is estimated to be approximately $24.5 \%, 27.0 \%, 31.2 \%$, and $29.9 \%$ of the gate capacitance based on the parallel plate model, respectively. Consequently, the average intrinsic $\mu$ of $\mathrm{ZrO}_{2}, \mathrm{AlZrO}_{x-1}, \mathrm{AlZrO}_{x-2}$, and $\mathrm{AlZrO}_{x-3}$ based TFTs are calculated to be 28.7, 30.6, 33.3, and $35.2 \mathrm{~cm}^{2} \mathrm{~V}^{-1} \mathrm{~s}^{-1}$, respectively. The average intrinsic $\mu$ of the devices are tested from the total of 25 devices. The results shows a very strong control on the electrical performance of s-SWCNT TFT by controlling the $\mathrm{Al}$ concentration in $\mathrm{AlZrO}_{x}$ insulator. The average mobility improvement of SWCNT TFTs with $\mathrm{AlZrO}_{x-3}$ insulator is attributed to smooth surface and low interface trap states, leading to the reduced probability of carrier scattering. The threshold voltage of the device is reduced from 3.2 to $-0.5 \mathrm{~V}$ with increasing Al content. The result is attributed to the increased capacitance with increasing $\mathrm{Al}$ content. More details are shown in Table 1.

The hysteresis of the device is observed in the $I_{\mathrm{DS}}$ versus $V_{\mathrm{GS}}$ characteristics as shown in Fig. 5. The hysteresis of $\mathrm{AlZrO}_{x-3}$
Table 1 The average electrical performance of SWCNT TFTs with different gate insulators

\begin{tabular}{llrlll}
\hline Device & $\begin{array}{l}\mu \\
\left(\mathrm{cm}^{2} \mathrm{~V}^{-1} \mathrm{~s}^{-1}\right)\end{array}$ & $V_{\mathrm{T}}(\mathrm{V})$ & $\begin{array}{l}\mathrm{SS} \\
(\mathrm{V} \mathrm{dec}\end{array}$ & $I_{\text {on }} / I_{\text {off }}$ & $\begin{array}{l}\text { Hysteresis } \\
(\mathrm{V})\end{array}$ \\
\hline $\mathrm{ZrO}_{2}$ & 28.7 & 3.2 & 0.15 & $1.2 \times 10^{4}$ & 1.43 \\
$\mathrm{AlZrO}_{x-1}$ & 30.6 & 2.3 & 0.12 & $2.5 \times 10^{4}$ & 1.01 \\
$\mathrm{AlZrO}_{x-2}$ & 33.3 & 1.8 & 0.10 & $8 \times 10^{4}$ & 0.2 \\
$\mathrm{AlZrO}_{x-3}$ & 35.2 & -0.5 & 0.09 & $3.7 \times 10^{5}$ & 0.1 \\
\hline
\end{tabular}

based TFT shows a small hysteresis of $0.1 \mathrm{~V}$, which is obviously smaller than that $(1.43 \mathrm{~V})$ of $\mathrm{ZrO}_{2}$ based TFT. Generally, hysteresis in the SWCNT transistor is attributed to trap states in the dielectric or SWCNT/dielectric interface. ${ }^{41}$ It is reported that hydroxyl groups $(-\mathrm{OH})$ present on the surface of dielectric layer is considered to be interface defects and significant contributors to hysteresis. ${ }^{42}$ Upon applying a gate bias of $3 \mathrm{~V}$, the negative charges formed on the surface of gate insulator can be trapped by $-\mathrm{OH}$ group. It facilitates the conduction during the forward sweep in gate voltage. Thus, the threshold voltage of the transistor will shift toward the positive direction. Conversely, a negative gate bias discharges - $\mathrm{OH}$ groups into their neutral states, thereby reducing the conductivity for hole transport during the reverse sweep. It suggests that $\mathrm{Al}$ doping can effectively reduce the trap states in the $\mathrm{ZrO}_{2}$ and SWCNT/insulator interface. The results also verified the above XRD and XPS analysis. The effect trap density of states $\left(N_{\text {trap }}\right)$ of semiconducting SWCNT TFTs can be estimated by the following equation $^{41,43}$

$$
\begin{gathered}
\mathrm{SS}=\mathrm{d} V_{\mathrm{GS}} / \mathrm{d}\left(\log I_{\mathrm{DS}}\right) \\
\mathrm{SS}=\frac{k T \ln 10}{e}\left[1+\frac{e^{2}}{C_{\mathrm{i}}} N_{\text {trap }}\right]
\end{gathered}
$$

where SS is the subthreshold swing, $k$ is the Boltzmann constant, $T$ is temperature, and $C_{\mathrm{i}}$ is the intrinsic capacitance. The effective trap density for $\mathrm{ZrO}_{2}, \mathrm{AlZrO}_{x-1}, \mathrm{AlZrO}_{x-2}$, and AlZrO $_{x-3}$ based TFTs are estimated to be $4.33 \times 10^{11}, 2.82 \times$ $10^{11}, 1.92 \times 10^{11}$, and $1.34 \times 10^{11} \mathrm{~cm}^{-2} \mathrm{eV}^{-1}$, respectively. $\mathrm{AlZrO}_{x-3}$ based TFTs shows a smaller trap density, which is attributed to smooth surface and less trap in $\mathrm{AlZrO}_{x-3}$ film. The effective trap density is obviously smaller than that of SWCNTTFTs with $\mathrm{SiO}_{2}$ and $\mathrm{SiN}_{x}$ gate dielectric. ${ }^{44}$

The negative gate bias stability of semiconducting SWCNT TFTs with different $\mathrm{AlZrO}_{x}$ insulators is evaluated. Fig. 6 shows the transfer characteristics $\left(V_{\mathrm{DS}}=-3 \mathrm{~V}\right)$ before and after bias stress at a $V_{\mathrm{GS}}$ of $-3 \mathrm{~V}$ for $1800 \mathrm{~s}$ in ambient air. For all devices, the transfer characteristics shift slightly toward the negative direction with increasing the stress time. The $V_{\mathrm{T}} \operatorname{shift}\left(\Delta V_{\mathrm{T}}\right)$ of the device with $\mathrm{AlZrO}_{x}$ insulator is smaller than that of the device with $\mathrm{ZrO}_{2}$ insulator under similar stress condition. $\Delta V_{\mathrm{T}}$ of $\mathrm{ZrO}_{2}, \mathrm{AlZrO}_{x-1}, \mathrm{AlZrO}_{x-2}$, and $\mathrm{AlZrO}_{x-3}$ based TFTs for $1800 \mathrm{~s}$ stress time is $5.01,3.24,2.5$, and $1.62 \mathrm{~V}$, respectively. It suggests that the negative bias stability is improved with increasing the Al content in $\mathrm{AlZrO}_{x}$ insulator. The negative gate bias instabilities of semiconducting SWCNT TFTs are generally considered to be due to the hole trapping at the interface between the 

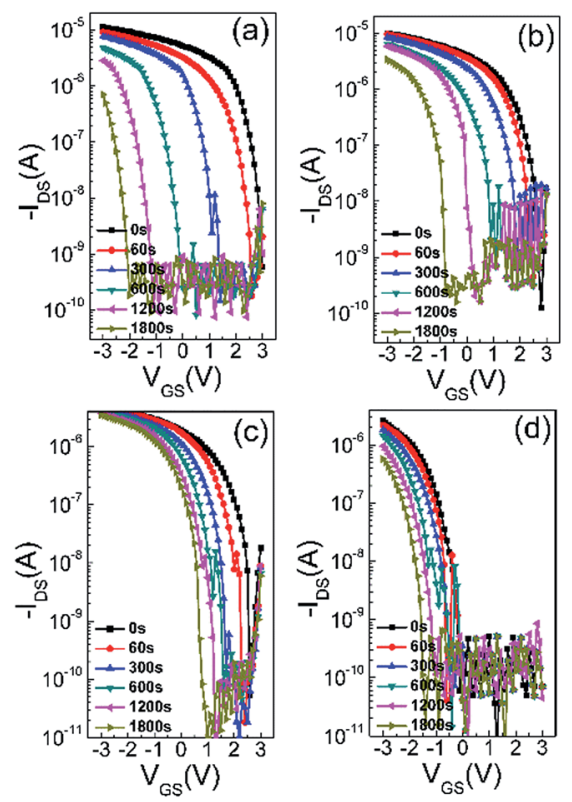

Fig. 6 The negative gate bias stability of semiconducting SWCNTTFTs with different gate insulators. (a) $\mathrm{ZrO}_{2}$, (b) $\mathrm{AlZrO}_{x-1}$, (c) $\mathrm{AlZrO}_{x-2}$, (d) $\mathrm{AlZrO}_{x-3}$.

semiconducting SWCNT channel layer and $\mathrm{ZrAlO}_{x}$ gate insulator or $\mathrm{ZrAlO}_{x}$ bulk gate insulator. The accumulated hole slowly fills up these trap states under negative gate bias stress. After removal of the stress voltage, the trapped charge can be slowly released again. In addition, the origin of the threshold voltage shift with stress time can be expressed by the stretched exponential model: ${ }^{45}$

$$
\left|\Delta V_{\mathrm{T}}\right|=\Delta V_{\mathrm{T} 0}\left\{1-\exp \left[-(t / \tau)^{\beta}\right]\right\}
$$

where $\Delta V_{\text {To }}$ is the saturated threshold voltage at infinite time, $\beta$ and $\tau$ are the exponent of the trapping rate and the relaxation time of the trapped charges, respectively. The obtained $\tau$ values are $6.59 \times 10^{2}, 8.24 \times 10^{2}, 1.24 \times 10^{3}$, and $2.63 \times 10^{3} \mathrm{~s}$ for semiconducting SWCNT TFT with $\mathrm{ZrO}_{2}, \mathrm{AlZrO}_{x-1}, \mathrm{AlZrO}_{x-2}$, and $\mathrm{AlZrO}_{x-3}$, respectively. It demonstrates that the degradation of $\mathrm{AlZrO}_{x}$ based TFT is slower than that of $\mathrm{ZrO}_{2}$-based TFT under a long-time operation. The long trapping time leads to capturing holes frequently at the gate dielectric or at the interface between the gate insulator and channel. Thus, it results in a small threshold voltage shift at the same stress conditions. Detailed comparison of the previous works has been shown in Table 2. It is easily seen that our SWCNT transistors have a high mobility and good stability.

The impact of temperature stress on the electrical performance of semiconducting SWCNT TFTs is also characterized. Fig. 7 shows the transfer curves of semiconducting SWCNT TFTs with temperature varying from 293 to $353 \mathrm{~K}$. For all of the devices, the on-state current and the mobility are enhanced with increasing temperature. It is reported that temperature dependent measurements of SWCNT TFTs is consistent with thermally activated transport. ${ }^{52}$ Thus, the thermally activated drain current can be described by the following relation: $I_{\mathrm{DS}} \propto \exp \left(-E_{\mathrm{a}} / k T\right)$,
Table 2 Comparison of electrical performance for SWCNT TFTs

\begin{tabular}{|c|c|c|c|c|}
\hline Ref. & $\begin{array}{l}\mu \\
\left(\mathrm{cm}^{2} \mathrm{~V}^{-1} \mathrm{~s}^{-1}\right)\end{array}$ & $V_{\mathrm{T}}(\mathrm{V})$ & $I_{\mathrm{on}} / I_{\mathrm{off}}$ & $\begin{array}{l}\Delta V_{\mathrm{T}}(\mathrm{V}) \\
(\mathrm{PBS})\end{array}$ \\
\hline $\mathrm{SiO}_{2} / \mathrm{CNT}^{46}$ & 15.03 & -0.45 & $\sim 10^{5}$ & - \\
\hline $\mathrm{SiO}_{2} / \mathrm{CNT}^{47}$ & $\sim 38$ & $0-1$ & $\sim 10^{5}$ & - \\
\hline $\mathrm{SiO}_{2} / \mathrm{CNT}^{48}$ & 18 & 0 & $\sim 10^{6}$ & 一 \\
\hline Ion-gel/CNT ${ }^{49}$ & $>100$ & $-1.0-1.5$ & 138 & - \\
\hline $\mathrm{BTO} / \mathrm{CNT}^{50}$ & 0.21 & -1.8 & $\sim 10^{3}$ & - \\
\hline PV3D3/CNT ${ }^{51}$ & 9.76 & $<4 \mathrm{~V}$ & $3 \times 10^{4}$ & - \\
\hline Our work & 35.2 & -0.5 & $3.7 \times 10^{5}$ & 1.62 \\
\hline
\end{tabular}
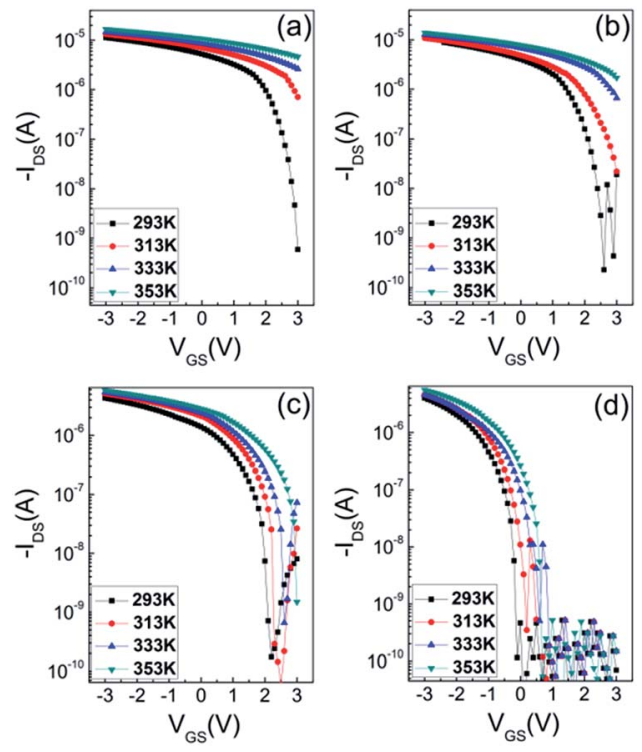

Fig. 7 The transfer curves of semiconducting SWCNT TFTs with temperature varying from 293 to $353 \mathrm{~K}$. (a) $\mathrm{ZrO}_{2}$, (b) $\mathrm{AlZrO}_{x-1}$, (c) $\mathrm{AlZrO}_{x-2}$, (d) $\mathrm{AlZrO}_{x-3}$.

where $T$ and $E_{\text {a }}$ are temperature and activation energy, respectively. At high temperature, polarons are thermally activated to hop between localized states in a faster manner, resulting in high mobility. In addition, the threshold voltage shift of the device under same temperature stress decreases with increasing Al content in the $\mathrm{AlZrO}_{x}$ insulator. The device with $\mathrm{AlZrO}_{x-3}$ shows a small threshold voltage shift of $1.18 \mathrm{~V}$ under the temperature stress of $353 \mathrm{~K}$. It is reported that the threshold voltage shift is correlated with the total density of states, consisting of the density of states of the bulk channel and interface trap density. ${ }^{53}$ Thus, a smaller threshold voltage shift can be attributed to the fact that adding $\mathrm{Al}$ into $\mathrm{ZrO}_{2}$ film can improve the surface roughness and reduce interface trap states. The result is consistent with the previous conclusion.

\section{Conclusions}

In summary, $\mathrm{AlZrO}_{x}$ films with different $\mathrm{Al}$ contents have been successfully prepared by atomic layer deposition. Increasing $\mathrm{Al}$ concentration in the $\mathrm{AlZrO}_{x}$ insulator can reduce leakage current and decrease the surface roughness of $\mathrm{AlZrO}_{x}$ insulator. 
$\mathrm{AlZrO}_{x-3}$ thin film shows a low leakage current density of $3.5 \times$ $10^{-9} \mathrm{~mA} \mathrm{~cm}^{-2}$ at the electrical field strength of $2 \mathrm{MV} \mathrm{cm}^{-1}$ and a small rms of $0.46 \mathrm{~nm}$. The SWCNT TFT based on $\mathrm{AlZrO}_{x}$ with $\mathrm{AlZrO}_{x-3}$ gate insulator exhibits a superior electrical performance with an average mobility of $35.2 \mathrm{~cm}^{2} \mathrm{~V}^{-1} \mathrm{~s}^{-1}$, a high on/ off ratio of $3.7 \times 10^{5}$, a low subthreshold swing of 0.09 , and a little hysteresis of $0.1 \mathrm{~V}$, and a small threshold voltage shift of $1.62 \mathrm{~V}$ under negative bias stress of $-3 \mathrm{~V}$ for $1800 \mathrm{~s}$. The improvement of electrical performance and stability for SWCNT TFT with $\mathrm{AlZrO}_{x}$ insulator is attributed to the smooth surface and less $\mathrm{AlZrO}_{x} / \mathrm{SWCNT}$ interface trap. It suggests that $\mathrm{AlZrO}_{x}$ film combining the advantage of $\mathrm{ZrO}_{2}$ and $\mathrm{Al}_{2} \mathrm{O}_{3}$ is a promising candidate as gate insulator for achieving high performance and more reliable solution-processed semiconducting SWCNT TFTs.

\section{Conflicts of interest}

There are no conflicts to declare.

\section{Acknowledgements}

The authors would like to acknowledge the financial support given by the Natural Science Foundation of China (61774100, 51302165), Shanghai Science and Technology Commission (15JC1402000) and National Key Research and Development Program of China (2016YFB0401105).

\section{Notes and references}

1 C. M. Homenick, R. James, G. P. Lopinski, J. Dunford, J. Sun, H. Park, Y. Jung, G. Cho and P. R. L. Malenfant, ACS Appl. Mater. Interfaces, 2016, 8, 27900.

2 C. Qiu, Z. Zhang, M. Xiao, Y. Yang, D. Zhong and L. M. Peng, Science, 2017, 355, 271.

3 C. Cao, J. B. Andrews, A. Kumar and A. D. Franklin, ACS Nano, 2016, 10, 5221.

4 B. Kim, S. Jang, M. L. Geier, P. L. Prabhumirashi, M. C. Hersam and A. Dodabalapur, Appl. Phys. Lett., 2014, 104, 062101.

5 K. R. Reddy, K. P. Lee, A. I. Gopalan, M. S. Kim, A. M. Showkat and Y. C. Nho, J. Polym. Sci., Part A: Polym. Chem., 2006, 44, 3355.

6 M. U. Khan, K. R. Reddy, T. Snguanwongchai, E. Haque and V. G. Gomes, Colloid Polym. Sci., 2016, 294, 1599.

7 M. Cakici, K. R. Reddy and F. Alonso-Marroquin, Chem. Eng. J., 2017, 309, 151.

8 B. Mortazavi, Carbon, 2017, 118, 25.

9 S. J. Kang, C. Kocabas, T. Ozel, M. Shim, N. Pimparkar, M. A. Alam, S. V. Rotkin and J. A. Rogers, Nat. Nanotechnol., 2007, 2, 230.

10 B. K. Sarker, N. Kang and S. I. Khondaker, Nanoscale, 2014, 6, 4896.

11 K. R. Reddy, B. C. Sin, C. H. Yoo, W. Park, K. S. Ryu, J. S. Lee, D. Sohn and Y. Lee, Scr. Mater., 2008, 58, 1010.

12 M. S. Arnold, A. A. Green, J. F. Hulvat, S. I. Stupp and M. C. Hersam, Nat. Nanotechnol., 2006, 1, 60.
13 M. Jang, S. Kim, H. Jeong and S. Y. Ju, Nanotechnology, 2016, 27, 41LT01.

14 B. S. Flavel, K. E. Moore, M. Pfohl, M. M. Kappes and F. Hennrich, ACS Nano, 2014, 8, 1817.

15 H. Liu, T. Tanaka and H. Kataura, Nano Lett., 2014, 14, 6237. 16 Z. Li, J. Ding, J. Lefebvre and P. R. L. Malenfant, Org. Electron., 2015, 26, 15.

17 T. Lei, X. Chen, G. Pitner, H. S. Philip Wong and Z. Bao, J. Am. Chem. Soc., 2016, 138, 802.

18 R. S. Park, M. M. Shulaker, G. Hills, L. S. Liyanage, S. Lee, A. Tang, S. Mitra and H. S. P. Wong, ACS Nano, 2016, 10, 4599.

19 B. Kim, S. Jang, P. L. Prabhumirashi, M. L. Geier, M. C. Hersam and A. Dodabalapur, Appl. Phys. Lett., 2013, 103, 082119.

20 C. W. Lee, S. K. R. Pillai, X. N. Luan, Y. L. Wang, C. M. Li and M. B. Chan-Park, Small, 2012, 8, 2941.

$21 \mathrm{~W} . \mathrm{Hu}, \mathrm{B}$. Frost and R. L. Peterson, J. Phys. D: Appl. Phys., 2016, 49, 115109.

22 S. Yadav and S. Ghosh, ACS Appl. ACS Appl. Mater. Interfaces, 2016, 8, 10436.

23 D. W. Park, S. Mikael, T. H. Chang, S. Gong and Z. Ma, Appl. Phys. Lett., 2015, 106, 102106.

24 Y. Lee, W. Jeon, Y. Cho, M. H. Lee, S. J. Jeong, J. Park and S. Park, ACS Nano, 2016, 10, 6659.

25 Y. Widjaja and C. B. Musgravea, Appl. Phys. Lett., 2002, 80, 3304.

26 J. H. Zhang, H. Zhang, Y. Q. Zheng, M. J. Wei, H. Ding, B. Wei and Z. L. Zhang, Nanotechnology, 2017, 28, 044002.

27 J. Meyer, H. Schmidt, W. Kowalsky, T. Riedl and A. Kahn, Appl. Phys. Lett., 2010, 96, 243308.

28 J. Oh, S. Shin, J. Park, G. Ham and H. Jeon, Thin Solid Films, 2016, 599, 119.

29 W. Hu, B. Frost and R. L. Peterson, J. Phys. D: Appl. Phys., 2016, 49, 115109.

30 P. Jin, G. He, D. Xiao, J. Gao, M. Liu, J. Lv, Y. Liu, M. Zhang, P. Wang and Z. Sun, Ceram. Int., 2016, 42, 6761.

31 S. S. Jiang, G. He, J. Gao, D. Q. Xiao, P. Jin, W. D. Li, J. G. Lv, M. Liu, Y. M. Liu and Z. Q. Sun, Ceram. Int., 2016, 42, 11640.

32 M. D. Morales-Acosta, M. A. Quevedo-López and R. RamírezBon, Mater. Chem. Phys., 2014, 146, 380.

33 A. Bhoolokam, M. Nag, A. Chasin, S. Steudel, J. Genoe, G. Gelinck, G. Groeseneken and P. Heremans, J. Inf. Disp., 2015, 16, 31.

34 T. J. Park, J. H. Kim, J. H. Jang, C. K. Lee, K. D. Na, S. Y. Lee, H. S. Jung, M. Kim, S. Han and C. S. Hwang, Chem. Mater., 2010, 22, 4175.

35 X. D. Huang, R. P. Shi, J. K. O. Sin and P. T. Lai, IEEE Trans. Device Mater. Reliab., 2016, 16, 38.

36 R. Suri, C. J. Kirkpatrick, D. J. Lichtenwalner and V. Misra, Appl. Phys. Lett., 2010, 96, 042903.

37 M. J. Guittet, J. P. Crocombette and M. Gautier-Soyer, Phys. Rev. B, 2001, 63, 125117.

38 L. Zhang, J. Li, X. W. Zhang, X. Y. Jiang and Z. L. Zhang, Appl. Phys. Lett., 2009, 95, 072112. 
39 A. Javey, H. Kim, M. Brink, Q. Wang, A. Ural, J. Guo, P. Mcintyre, P. Mceuen, M. Lundstrom and H. J. Dai, Nat. Mater., 2002, 1, 241.

40 Q. Cao, M. G. Xia, C. Kocabas, M. Shim, J. A. Rogers and S. V. Rotkin, Appl. Phys. Lett., 2007, 90, 023516.

41 T. J. Ha, D. Kiriya, K. Chen and A. Javey, ACS Appl. Mater. Interfaces, 2014, 6, 8441.

42 S. H. Jin, A. E. Islam, T. Kim, J. Kim, M. A. Alam and J. A. Rogers, Adv. Funct. Mater., 2012, 22, 2276.

43 J. Li, C. X. Huang, J. H. Zhang, W. Q. Zhu, X. Y. Jiang and Z. L. Zhang, RSC Adv., 2015, 5, 9621.

44 T. J. Ha, Electron. Mater. Lett., 2017, 13, 287.

45 S. W. Lee, S. Y. Lee, S. C. Lim, Y. D. Kwon, J. S. Yoon, K. Uh and Y. H. Lee, Appl. Phys. Lett., 2012, 101, 053504.

46 X. Cao, F. Wu, C. Lau, Y. Liu, Q. Liu and C. Zhou, ACS Nano, 2017, 11, 2008.
47 Z. Li, J. Ding, J. Lefebvre and P. R. L. Malenfant, Org. Electron., 2015, 26, 15.

48 J. Y. Jeon and T. J. Ha, IEEE Trans. Electron Devices, 2016, 63, 827.

49 J. Vaillancourt, H. Zhang, P. Vasinajindakaw, H. Xia, X. Lu, X. Han, D. C. Janzen, W. S. Shih, C. S. Jones, M. Stroder, M. Y. Chen, H. Subbaraman, R. T. Chen, U. Berger and M. Renn, Appl. Phys. Lett., 2008, 93, 243301.

50 J. Noh, M. Jung, K. Jung, G. Lee, S. Lim, D. Kim, S. Kim, J. M. Tour and G. Cho, Org. Electron., 2011, 12, 2185.

51 D. Lee, J. Yoon, J. Lee, B. H. Lee, M. L. Seol, H. Bae, S. B. Jeon, H. Seong, S. G. Im, S. J. Choi and Y. K. Choi, Sci. Rep., 2016, 6, 26121.

52 D. E. Johnston, M. F. Islam, A. G. Yodh and A. T. Johnson, Nat. Mater., 2005, 4, 589.

53 C. X. Huang, J. Li, Y. Z. Fu, J. H. Zhang, X. Y. Jiang and Z. L. Zhang, Appl. Phys. Lett., 2015, 107, 213504. 